\title{
WORKSHOP PENERAPAN TEKNOLOGI INFORMASI APLIKASI CANVA DALAM MENINGKATKAN KUALITAS SDM REMAJA KARANG TARUNA
}

\author{
Dwi Andini Putri ${ }^{1}$, Kusmayanti Solecha ${ }^{2}$, Siti Nurwahyuni ${ }^{3}$, Suparni $^{4}$ \\ 1,2,3,4Program Studi Teknologi Informasi, Universitas Bina Sarana Informatika \\ *Coresponding-Author: dwi.dwd@bsi.ac.id
}

\begin{abstract}
ABSTRAK. Desain grafis adalah suatu media untuk menyampaikan informasi melalui bahasa komunikasi visual dalam wujud dwimatra ataupun trimatra yang melibatkan kaidah-kaidah estetik. Penggunaan teknologi informasi menjadi salah satu sarana penyampaian informasi dan aspirasi dalam masyarakat secara umum serta organisasi secara khusus. Untuk itu para Pengurus Karang Taruna Kecamatan Ciomas yang merupakan salah satu pendukung pemerintahan Desa, dan sebagai penyalur kegiatan masyarakat, serta pelengkap pemerintahan desa menggandeng para pemuda untuk dapat meningkatkan keberdayaan masyarakat khususnya kaum muda di berbagai bidang yang berorientasi pada peningkatan kesejahteraan sosial dan ekonomi, terutama membantu Karang Taruna Kecamatan Ciomas dalam mencapai tujuan dan pelayanan yang ingin ditingkatkan dengan mengadakan Design Grafis Milenial Menggunakan Aplikasi Canva yang dilaksanakan secara online. hasil yang diperoleh dalam kegiatan ini adalah meningkatkan kualitas tampilan produk, meningkatkan pemasaran, kualitas manajemen, asset serta Omset.
\end{abstract}

Kata Kunci: workshop, teknologi informasi, aplikasi canva

\begin{abstract}
Graphic design is a medium to convey information through visual communication in the form of two or three dimensions that involve the application of aesthetic principles. The use of information technology is one of the means of conveying information and aspirations in society in general and in organizations in particular. For this reason, the Karang Taruna Management in Ciomas District, who is one of the supporters of the village government, and as a channel for community activities, as well as village complements, cooperates with youths to be able to increase community empowerment, especially young people in various fields that improve social and economic welfare, especially helping Karang Taruna. Ciomas District cadets in order to improve the implementation of Millennial Graphic Design Using Canva which is carried out online. The results obtained in this activity are improving the quality of product display, improving marketing, management quality, assets, and turnover.
\end{abstract}

Keywords: workshop, information technology, canva apps

\section{PENDAHULUAN}

Desain grafis adalah suatu media untuk menyampaikan informasi melalui bahasa komunikasi visual dalam wujud dwimatra ataupun trimatra yang melibatkan kaidah-kaidah estetik. Dalam jurnal (Dewojati, 2015) juga menjelaskan Desain grafis merupakan bagian dari desain komunikasi visual dan mulai berkembang dalam situasi yang saling mempengaruhi atau hubungan interelasi baik dalam gaya desain grafis itu sendiri maupun dalam hubungannya dengan masyarakat. Sedangkan teknologi informasi menjadi salah satu media yang digunakan untuk membantu dalam melakukan promosi, mempermudah transaksi serta mempersingkat waktu saat membuat laporan. Banyak perusahaan yang semakin memikirkan pentingnya kunci sukses dalam memenangkan persaingan dunia bisnis, sangat bergantung pada kemampuan perusahaan untuk mendapatkan informasi yang berguna secara cepat dan tepat yang bertumpu pada nominal investasi (Miswanto et al., 2020). Penggunaan teknologi informasi menjadi salah satu sarana penyampaian informasi dan aspirasi 
dalam masyarakat secara umum serta organisasi secara khusus. Untuk itu para pengurus Pengurus Karang Taruna Kecamatan Ciomas yang merupakan salah satu pendukung pemerintahan Desa, dan sebagai penyalur kegiatan masyarakat, serta pelengkap pemerintahan desa menggandeng para pemuda untuk dapat meningkatkan keberdayaan masyarakat khususnya kaum muda di berbagai bidang yang berorientasi pada peningkatan kesejahteraan sosial dan ekonomi. Banyaknya aplikasi dan sistem yang saat ini telah dibuat dan bahkan dikembangkan oleh para programer serta melihat kebutuhan perusahaan yang membutuhkan aplikasi dalam bentuk website atau desktop (Supriyatna, 2018). Keberadaan media sosial menjadi sarana bagi konsumen yang dapat digunakan untuk menyebarkan informasi baik berupa teks, gambar, audio, dan video dengan banyak pihak baik antar perusahaan kepada konsumen atau konsumen pada perusahan(Kotler \& Kevin, 2012). Sistem Informasi Pelatihan dengan menggunakan teknologi web service berbasis website pada Pincher ID dapat berjalan dengan baik dengan hasil pengujian dari sistem dinyatakan layak dan secara fungsional sistem dapat menghasilkan output yang diharapkan(Somya \& Nathanael, 2019).

Penggunaan Desain Grafis merupakan salah satu strategi untuk meningkatkan keunggulan pasar dalam sebuah perusahaan biasa maupun berkelas internasional, produk, merk, dan promosi semua di desain agar dapat diterima masyarakat (Valentino \& Yudiansyah, 2018). Saat ini Pengurus Karang Taruna Kecamatan Ciomas yang diketuai oleh Ihwan Supian ingin meningkatkan pelayanan terhadap masyarakat dengan menyediakan informasi yang dapat diakses secara cepat, tepat dan akurat dengan cara menyajikan sebuah informasi yang memiliki desain yang menarik dan mudah saat publikasikan melalui media sosial. Oleh karena itu Perlunya diadakan pengabdian masyarakat adalah agar dapat menyeimbangkan kemampuan sumber daya manusia dengan perkembangan teknologi yang semakin hari kian pesat dan tidak terkendali.

\section{ANALISIS PERMASALAHAN}

Permasalahan-permasalahan yang dihadapi oleh Karang Taruna Kecamatan Ciomas adalah terjadi peralihan tren dalam mendapatkan informasi dari konvensional (offline) seperti media cetak ke media digital (online) kemudian kemampuan para remaja karang taruna dalam tehnik design grafis untuk membuat poster, logo, featured image blog, infografik, newsletter, konten media sosial, desain kemasan produk, invoice, thumbnail youtube, benner iklan dan lain-lain masih sangat kurang. Lalu kebutuhan akan pengetahuan mengenai pembuatan design untuk para remaja karang taruna kecamatan ciomas.

\section{Peta Lokasi Mitra}

Karang Taruna Kecamatan Ciomas beralamat di Blok N-O Jl. Raya Ciomas Kreteg No. 343 Pagelaran kota Bogor Provinsi Jawa Barat. jarak lokasi Mitra Pengabdian dengan kampus Universitas Bina Sarana Informatika $\pm 70 \mathrm{Km}$.

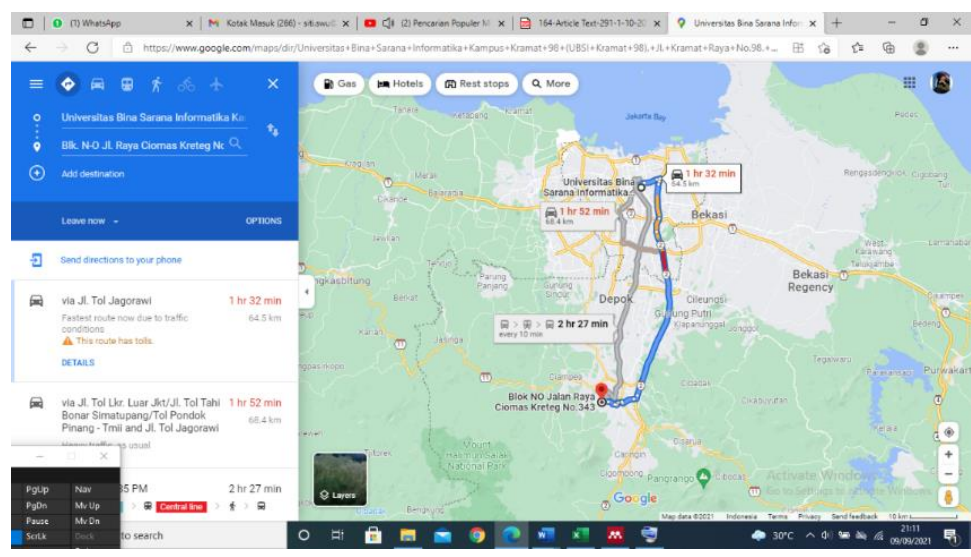

Gambar 1. Peta jarak lokasi Karang Taruna Kecamatan Ciomas dengan kampus Universitas Bina Sarana Informatika 


\section{SOLUSI YANG DITAWARKAN}

Solusi yang kami ajukan untuk menyelesaikan permasalahan mitra adalah

\section{Tahap 1}

Dengan adanya peralihan media penyampaian informasi, kami menyarankan untuk setiap remaja karang taruna kecamatan Ciomas mempelajari cara mendesign agar dapat menyajikan sebuah informasi pada media digital menjadi lebih menarik.

\section{Tahap 2}

Memberikan pembelajaran atau semacam pelatihan mengenai pembuatan design grafis untuk meningkatkan kompetensi para $\mathrm{R}$ karang taruna kecamatan ciomas dalam bidang design.

\section{Tahap 3}

Pelatihan design grafis menggunakan aplikasi canva akan diberikan secara bertahap dan berkesinambungan agar dapat diperoleh hasil yang maksimal

\section{HASIL DAN PEMBAHASAN}

Pelaksanaan workshop aplikasi canva pada remaja karang taruna kecamatan Ciomas dilakukan pada hari Minggu tanggal 12 September 2021 yang dilakukan secara online menggunakanaplikasi Zoom. Pelatihan berlangsung dari pukul 09.00 sampai dengan 15.00 . selama workshop berlansung para peserta sangat antusias karena disajikan dengen presentasi yang menari yg disampai kan oleh tutor. Dan banyak tanya jawab selama workshop berlangsung. Berikut merupakan gambaran pelaksanaan workshop aplikasi canva pada remaja karang taruna kecamatan Ciomas melalui aplikasi zoom meeting.

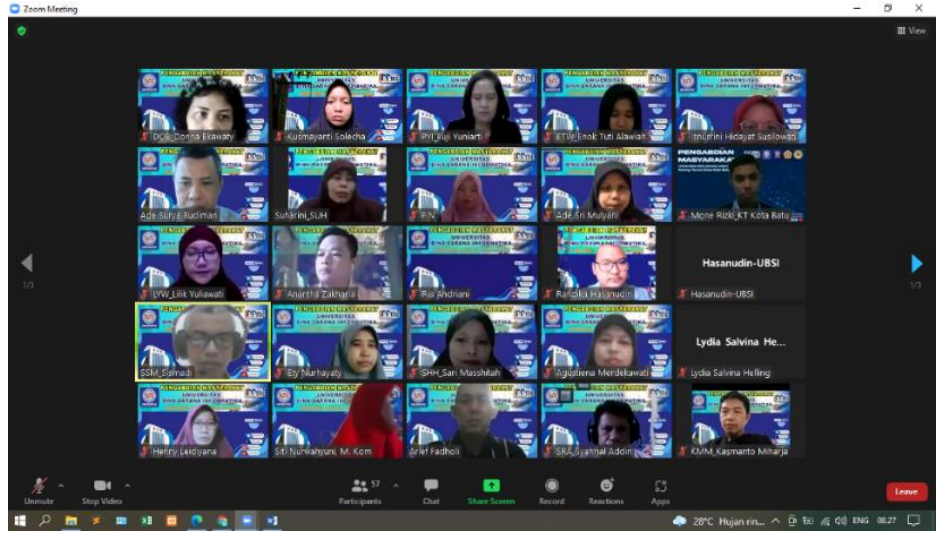

Gambar 1 Proses Pembukaan Kegiatan Pengabdian Masyarakat dengan tema Pelatihan Design Grafis Milenial Menggunakan Aplikasi Canva pada Karang Taruna Kecamatan Ciomas

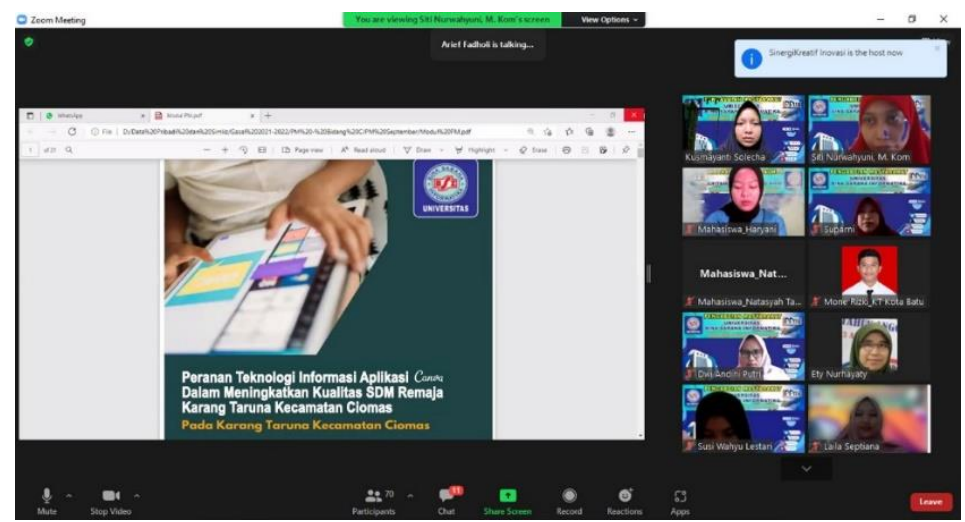

Gambar 2. Proses penyampaian materi pelatihan design grafis milenial menggunakan aplikasi canva pada Karang Taruna Kecamatan Ciomas 


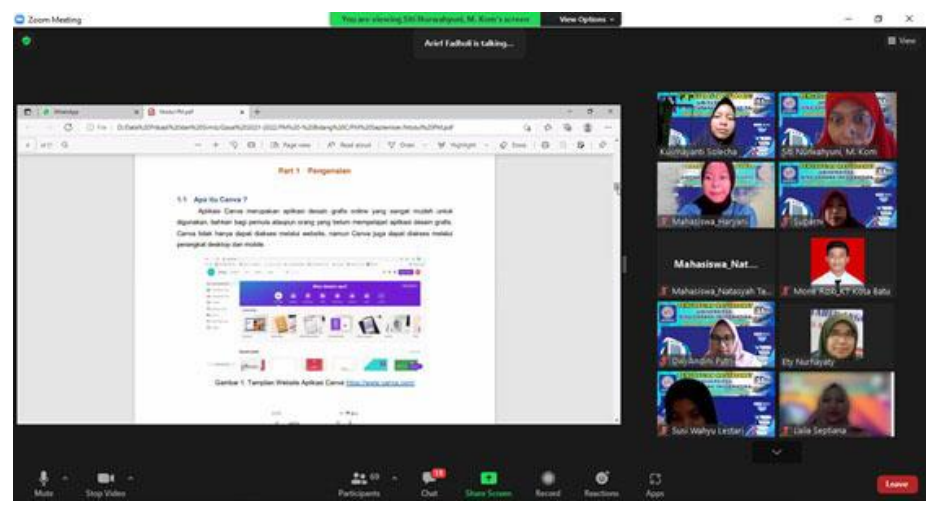

Gambar 3. Proses penyampaian materi Part 1. Pengenalan Aplikasi Canva

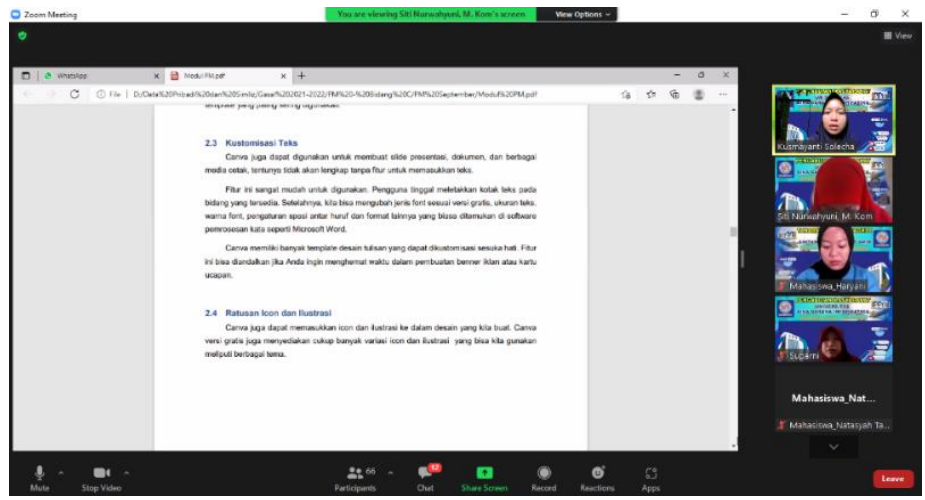

Gambar 4. Proses penyampaian materi Part 2 Fitur-fitur Gratis dalam Canva

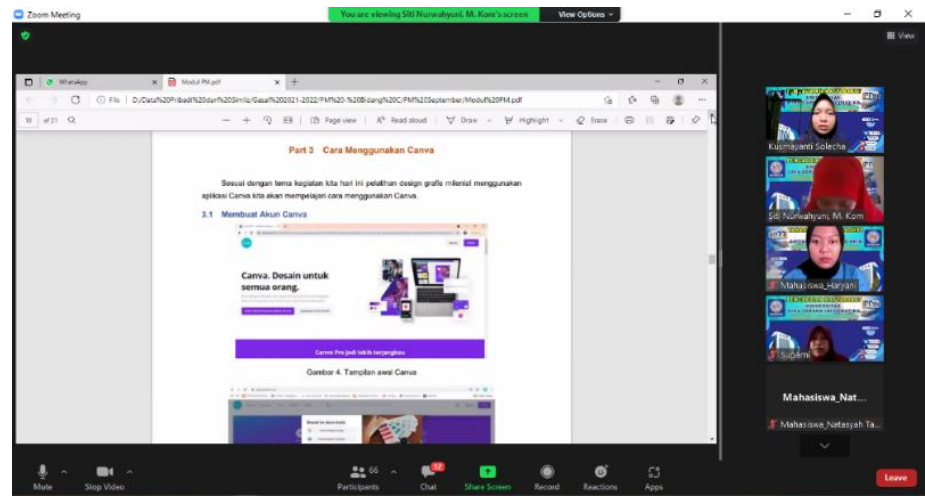

Gambar 5. Proses penyampaian materi Part 3 Cara Menggunakan Canva

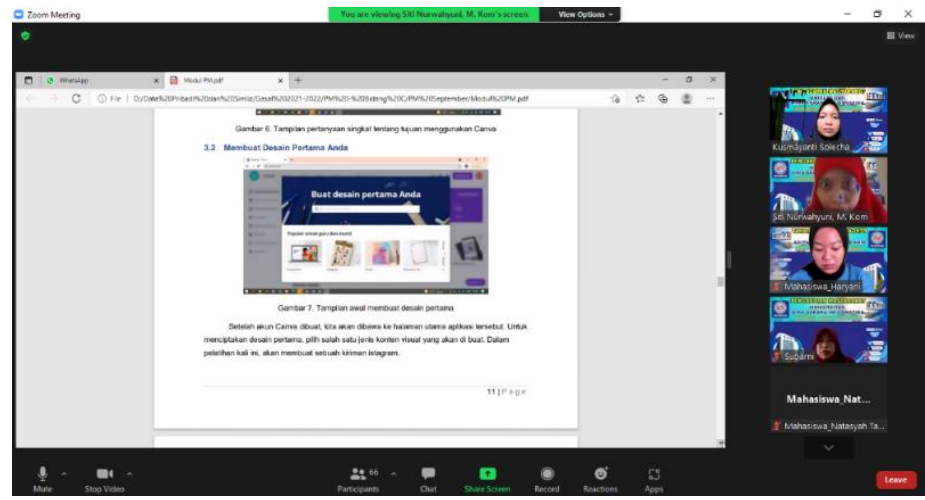

Gambar 6. Proses penyampaian membuat desain baru 


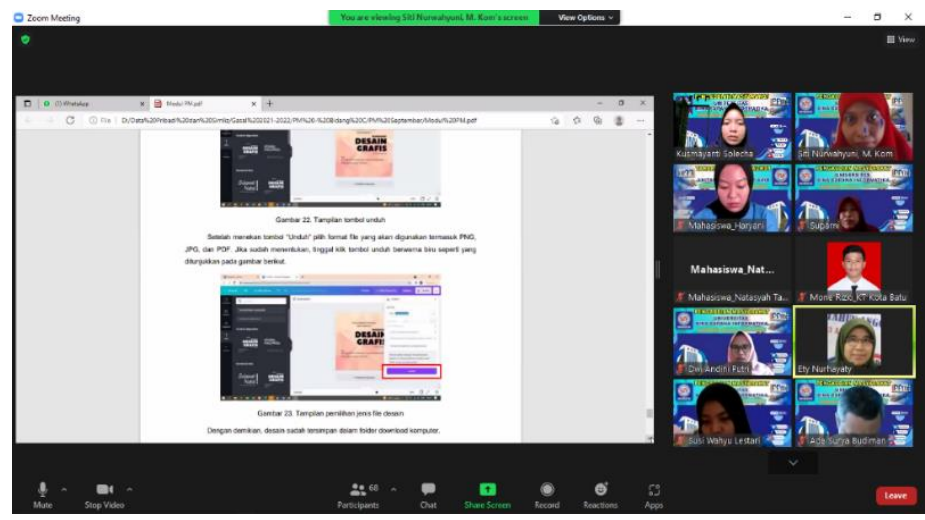

Gambar 7. Proses penyampaian materi mendownload hasil desain

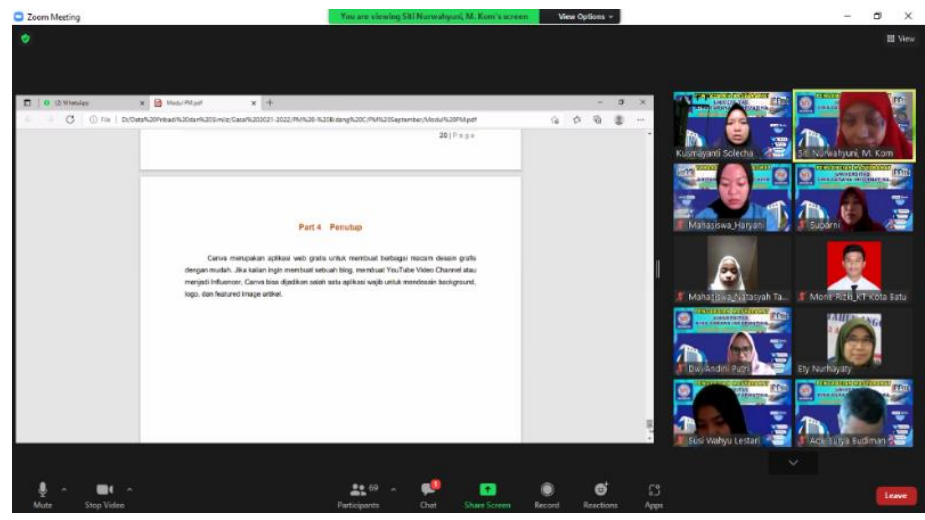

Gambar 8. Proses penyampaian materi selesai

Tabel 1. Manfaat yang diperoleh dari hasil workshop

\section{Permasalahan}

Terjadi peralihan tren dalam mendapatkan informasi dari konvensional (offline) seperti media cetak ke media digital (online).

\section{Kemampuan para remaja} karang taruna dalam tehnik design grafis untuk membuat poster, logo, featured image blog, infografik, newsletter, konten media sosial, desain kemasan produk, invoice, thumbnail youtube, benner iklan dan lain-lain masih sangat kurang.

Kebutuhan akan pengetahuan mengenai pembuatan design untuk para remaja karang taruna kecamatan ciomas.

\section{Solusi}

Memberikan pelatihan mengenai teknologi informasi seperti cara membuatan informasi dengan menggunakan aplikasi canva

\section{Memberikan pelatihan} mengenai tehnik design grafis untuk membuat poster, logo, featured image blog, infografik, newsletter, konten media sosial, desain kemasan produk, invoice, thumbnail youtube, benner iklan dan lain-lain menggunakan aplikasi canva

Memberikan pelatihan mengenai cara penggunaan fitur-fitur yang ada pada aplikasi canva.

\section{Keterangan}

Dampak yang dihasilkan para remaja karang taruna kecamatan ciomas mulai memahami tentang aplikasi canva sebagai media teknologi informasi.

Dampak yang dihasilkan para remaja karang taruna kecamatan ciomas sudah dapat mengimplementasikan sebagai media untuk membuat poster/benner sebagai bentuk penyajian informasi yang lebih menarik.

Dampak yang dihasilkan para remaja karang taruna kecamatan ciomas sudah mengetahui cara penggunaan fitur-fitur pada aplikasi canva, seperti membuat poster, logo, featured image blog, infografik, newsletter, konten media sosial, desain kemasan produk, invoice, thumbnail youtube, benner iklan dll. 
Setelah pelaksanaan workshop penerapan teknologi informasi aplikasi canva sebagai upaya dalam meningkatkan kualitas sdm remaja karang taruna kecamatan ciomas. Workshop penerapan teknologi informasi aplikasi canva ini juga diharapkan dapat meningkatkan kemampuan para remaja karang taruna dalam tehnik design grafis untuk membuat poster, logo, featured image blog, infografik, newsletter, konten media sosial, desain kemasan produk, invoice, thumbnail youtube, benner iklan dan lain-lain. Sehingga karang taruna kecamatan ciomas dapat memberikan kemudahan dalam penyamaian informasi secara online dengan tampilan yang lebih menarik. Untuk itu kampus Universitas Bina Sarana Informatika dari Prodi Teknik Informasi mengadakan Pengabdian Masyarakat yang diharapkan dapat meningkatkan kualitas sdm remaja karang taruna kecamatan ciomas.

\section{KESIMPULAN}

Kesimpulan dari terlaksananya pelatihan pembuatan desain yang dilakukan secara online menggunakan aplikasi zoom, dikarenakan masih dalam masa pandemic covid-19, workshop pembuatan desain ini merupakan salah satu strategi untuk meningkatkan keunggulan pasar dalam sebuah produk, merk, dan promosi semua di desain agar dapat diterima masyarakat. Walaupun workshop belum dapat dilaksanakan secara tatap muka langsung, akan tetapi antusias para peserta sangat besar dalam mengikuti pelatihan, sehingga ilmu yang disampaikan diarapkan dapat diterima dan diaplikasikan dengan baik. Serta adapun saran dari hasil pelaksanaan workshop pembuatan desain ini yaitu diharapkan dengan meningkatnya kemampuan para anggota karang taruna dalam hal pembuatan desain, maka dapat pula meningkatkan kualitas produk dan daya jual menjadi lebih menarik, serta dapat menyalurkan kreatifitas dengan cara yang positif melalui desain-desain yang lebih menarik.

\section{REFERENSI}

Dewojati, R. K. W. (2015). Desain Grafis Sebagai Media Ungkap Periklanan. Imaji, 7(2). https://doi.org/10.21831/imaji.v7i2.6633

Kotler, P., \& Kevin, L. K. (2012). Marketing management 13. Pearson Prentice Hall, Inc.

Miswanto, Sulistiani, H., \& Damayanti. (2020). PENERAPAN METODE COST AND BENEFIT ANALYSIS DALAM PENGUKURAN INVESTASI TEKNOLOGI INFORMASI (STUDY KASUS: CV LAUT SELATAN JAYA) The Application of Cost and Benefit Analysis Methods in Measuring Information Technology Investment (Case Study: CV Laut Sel. Jurnal Tekno Kompak, 14(1), 54-61.

Somya, R., \& Nathanael, T. M. E. (2019). Pengembangan Sistem Informasi Pelatihan Berbasis Web Menggunakan Teknologi Web Service Dan Framework Laravel. Jurnal Techno Nusa Mandiri, 16(1), 51-58. https://doi.org/10.33480/techno.v16i1.164

Supriyatna, A. (2018). Penerapan Usability Testing Untuk Pengukuran. Jurnal Ilmiah Teknologi - Informasi Dan Sains (TeknolS) Volume, 8(1), 1-16.

Valentino, D. E., \& Yudiansyah. (2018). PERANCANGAN DESAIN GRAFIS SEBAGAI MEDIA PROMOSI PADA NOVENA HOTEL BANDUNG. Jurnal Teknologi Informasi Dan Komunikasi Vol. 5, No. 2 Desember 2018, 5(2), 68-77. 